Analytical Design Planning Technique: a model of the detailed building design process

Simon Austin, Andrew Baldwin, Baizhan Li and Paul Waskett

Department of Civil and Building Engineering

Loughborough University

LE11 3TU, UK

Design Studies, Vol. 20, No.3, pp 279-296 


\title{
Analytical Design Planning Technique: a model of the detailed building design process
}

\author{
ABSTRACT \\ Current planning practice takes little account of the interdisciplinary, iterative nature of the \\ building design process. This leads to a compromised design process containing inevitable \\ cycles of rework together with associated time and cost penalties in both design and \\ construction. The Analytical Design Planning Technique (ADePT) is a planning methodology \\ which helps to overcome these difficulties. This paper describes the development of a modelling \\ notation and model of the detailed building design process, which forms the first stage of \\ ADePT.
}

KEYWORDS

design management, design techniques, modelling, planning, information processing 


\section{INTRODUCTION}

In recent times there has been a growing understanding of the importance of effective design management to facilitate a co-ordinated design within budget, and to ensure the smooth running of the project. Traditionally, building design has been planned by the same methods used to programme construction. These techniques do not allow the effect of variations and delays to be fully understood within an iterative process such as design. They monitor progress based upon the completion of drawing work and other 'design deliverables' as opposed to the availability of key pieces of information. The ADePT methodology shown in figure 1 was devised to overcome these limitations ${ }^{1}$, and associated computer tools have been developed to facilitate more effective planning and management of building design ${ }^{2}$. The first stage of the methodology is a model of the building design process, representing design activities and their information requirements. The data in this model is linked via a dependency table to a dependency structure matrix (DSM) analysis tool ${ }^{3}$ which is used in the second stage to identify iteration within the design process and schedule the activities with the objective of optimising the task order. The third stage of the methodology produces design programmes based on the optimised process sequence. The technique requires some iteration between the matrix and programming stages.

This paper describes a review of existing design models and modelling techniques, the establishment of a modelling notation to suit the building design process, the development and validation of a non-specific design process model (DPM) and the testing of this model, via the formulation of project-specific models. A full exposition of the complete ADePT methodology and detailed descriptions of the dependency structure matrix and programming stages are given elsewhere ${ }^{4,5,6}$.

\section{MODELS OF DESIGN PROCESSES}

Since the 1970s many models of the design process, both descriptive and prescriptive, and general and specific to a particular application, have been devised. This represents a clear recognition that attempts should be made to understand the process. 


\subsection{Existing Models of Design}

A literature review has identified many attempts to model design in general, engineering design and parts of the building design process. The models of product and engineering design that were reviewed, revealed two recurring themes. Most models represent the process at a 'high level', acting as an overview of the process, containing very little in the way of detail. The second recurring feature is that, by accident or design, they describe the overall process in terms of the stages within it. Among the best known models is Pugh's ${ }^{7}$ 'total design' model, generically covering all design processes. The VDI model of engineering design ${ }^{8}$ and the Pahl \& Beitz ${ }^{9}$ design model represent two of the best known models of engineering design.

The most widely used model of building design is the RIBA Plan of Work for Design Team Operation ${ }^{10}$. This sets out the details of work to be carried out by each profession during each stage of the design process, but differs from most other models in that it does not show 'links' of information between activities to indicate how particular tasks are related.

Pugh further developed his 'total design model' to produce a 'business design activity model $^{\prime 11,12}$. This showed how the model could be made business or industry specific. By way of an example, he represented building design. This model shares the same features as the total design model' in that it is an overview of the process. Sheath et al ${ }^{13}$ describe the basis for a model of design and construction termed the process protocol. Again this model examines the process at an overview level in terms of its stages but is also divided into eight management functions, including design management. Collaborative research is currently underway to build a second level of detail into the protocol, which will have linkages with the model described here.

Sanvido \& Norton ${ }^{14}$ produced a high level model of building design using an established modelling technique termed IDEF0 (Integrated Computer-Aided Manufacturing Definition), and therefore differing from most other models because the system of representation followed set rules. Karhu et al ${ }^{15}$ also adopted the IDEF0 technique to model the building design and construction process at a high level. The approach of using a recognised notation to construct a 
model had not been considered by the producers of most other models. However, Austin at al ${ }^{1}$ and Baldwin et al16 have combined the level of detail in the RIBA Plan of Work with information 'links' to achieve in-depth models of the different stages of the building design process using data flow diagrams. Data flow diagrams enable a model to be devised at the overview level, and then decomposed to reveal finer detail. Baldwin et al ${ }^{16}$ produced a model of the concept and scheme design stages of a project, while Austin et al ${ }^{1}$ developed a model of the civil and structural engineering elements of the detailed design stage. These works, and those of Sanvido \& Norton ${ }^{14}$ and Karhu et al ${ }^{15}$ each developed a model of building design using a recognised modelling technique because they required their models to be of use as part of broader, more complex systems.

\subsection{Modelling Techniques}

Many modelling methodologies have been examined to identify one that is most suited to representing information flow in detailed building design. Possible methodologies include: data flow diagrams; IDEF techniques (including IDEF0); entity relationship diagrams; hierarchical plus input-process-output diagrams; Jackson diagrams; object-orientated modelling systems; and Petri nets. Each of these techniques has advantages in modelling certain types of activity or data. Data flow diagrams and IDEF0 were identified as the most suitable techniques to produce a model of building design for use in the wider context of the ADePT methodology. The two techniques offer similar features, but data flow diagrams were originally favoured because of the work of Austin et al ${ }^{1}$. However, following a detailed evaluation of the two methodologies and a review of recent trends in process modelling, it was decided that IDEF0 would be the most appropriate notation.

\subsubsection{IDEF0 Modelling}

The IDEF methodologies were devised in the 1970s for use in the U.S. aerospace industry. By the mid-1970s they were in use in Europe and are now notable among modelling techniques for their wide range of usage, particularly IDEF $0^{17}$. IDEF techniques were developed in order to better communicate and analyse manufacturing in an attempt to improve productivity. This 
would be achieved through modelling information, dynamics and functions and processes ${ }^{18}$. Court et a ${ }^{19}$ undertook a comparison of various modelling techniques, including the IDEF techniques. Functional modelling is achieved with IDEF0. A process can be represented from the viewpoint of the information within it, rather than of its sub-processes, which has been identified as a requirement of a building design model. The technique is easy to use and understand, which is very important if the model is to be modified very quickly at the start of a building project and maintained throughout it. Each activity in the process transforms an information input into an output, and the internal mechanics of that transformation are not modelled. Figure 2 shows the notation of the IDEF0 technique. Each activity or process can be partitioned to show finer detail on another diagram, ensuring a single diagram does not become too cumbersome.

In most respects, the features of IDEF0 models are the same as data flow diagrams. The common features of IDEF0 modelling and data flow diagrams are: they are capable of topdown analysis; the top-down nature of the methods allows the top parts to be read to obtain an overview of the system and if more detail is required the lower levels can be studied; they are easily readable because of their graphical nature; the models are a manageable size (no diagram is larger than an A4 sheet); they represent a system from a viewpoint of data rather than a viewpoint of an organisation so a model can represent more than one organisation's operations; the consistency of the diagrams can be easily checked; they can model iterative procedures; they can model the aspect of choice; they do not describe how a task should be done, just what is needed to perform that task and what it is transformed into; and they do not show a sequence of activities. The distinguishing features of IDEF0 are that it emphasises the flow and control of data and process mechanisms or resources can be represented, while data flow diagrams allow the physical source of data to be shown. IDEF0 diagrams have a number of characteristics that mean they require careful use and a clear understanding to be maintained: they appear, at a superficial level, deceptively simple in their presentation and use; they can give a 'false sense' of sequence; and it is difficult, at a glance, to decide where some of the data has originated from. These disadvantages were outweighed by the benefits of adopting the IDEF0 
methodology, particularly if it is modified to suit the characteristics of the building design process.

\subsubsection{IDEF0v: A Modified Version of the IDEF0 Technique}

The review of the IDEF0 methodology found that although the technique is suitable to model the detailed building design process, some modifications could be made to the notation to enhance its advantages, particularly with the control and resource. The purpose of the ADePT model is to represent information requirements (i.e. constraints) and not to indicate how each design task should be undertaken. In this context there is little benefit to be gained from representing separate process controls in the model. Also, activity mechanisms (architect, civil engineer, etc.) would show little other than the discipline to which the activity belongs, and this attribute is implicit from the hierarchical structure of the model. It was decided that better use could be made of the top and bottom arrow features of an IDEF0 diagram by distinguishing the information inputs that are from activities in the same discipline, from those in other disciplines and from external sources such as the client, a regulating authority or an earlier stage of the design process. Discussions with designers and design managers suggests that this is of benefit, since the different types of information flow require different management priorities.

Figure 3 shows the notation implemented in the detailed building design process model (DPM), termed IDEF0v, which varies from the standard IDEF0 notation in the following ways:

- Intra-disciplinary inputs enter from the left

- Cross-disciplinary inputs enter from the top

- Inputs from external sources enter from the bottom

Tools that enable IDEF0 models to be constructed automatically distinguish between the different types of information input in a diagram. These tools will allow a model using IDEF0v to be compiled and will be able to distinguish between the different information inputs in their reporting facilities.

\section{CREATING THE DESIGN PROCESS MODEL (DPM)}


The Design Process Model (DPM) of detailed building design was developed in two stages. Initially, the activities within the overall process were identified and their hierarchical structure determined. Then the information requirements of each bottom level task were identified, allowing the DPM to be constructed. This combination of top-down and bottom-up analytical activities and the general features of the model are described below.

\subsection{Identifying the Detailed Building Design Hierarchy and Tasks}

\subsubsection{Determining the Design Process Hierarchy}

The overall process of detailed building design is defined in terms of a number of sub-processes and problems. Through a series of interviews with designers, design managers and design planners, this research has established a hierarchy of the sub-processes.

At the highest level is the process of detailed building design which is then partitioned into the sub-processes shown in figure 4.

The sub-processes are the design of all systems within the scope of responsibility of each of the five main design disciplines. Within each of the disciplines, designers were interviewed to determine the systems of the building that normally fall within the responsibility of that discipline, and also those that do so occasionally. The building's systems were then organised so they were within the part of the DPM that was deemed most appropriate. Discussions with designers then established how the design of each system of the building should be divided into sub-systems and components and how these should be further divided into the bottom level individual design tasks. The hierarchy of the process shows that detailed building design is partitioned into disciplines, systems, sub-systems or components and individual design tasks. The latter can be associated with the design of a component, a group of components or part of a component and is not partitioned further. Normally it is these individual design tasks that are represented in the dependency structure matrix and programming stages of the ADePT methodology, although analysis at a more abstract level is sometimes a helpful precursor.

\subsubsection{Determining the Information Requirements of the Tasks}


Having established the hierarchy of the activities in the detailed building design process, the information dependencies of each individual design task needed to be determined so that the DPM could be constructed. This information was collated in tabular form, via input from practising designers. The nature and source of each item of information was listed, regardless of whether it would normally have been available during the design of a building. This means that all the information required to allow the design to proceed was considered. The task number of both the task under consideration and the source activities within the same design discipline were determined by the process hierarchy.

\subsubsection{Producing Design Process Model Diagrams}

The DPM was compiled with a Computer-Aided Software Engineering (CASE) tool, by placing on to each diagram the activities identified in the process hierarchy and the information flows that each activity required. The source activity of each intra and cross-disciplinary information input was then identified. This was necessary because at the stage when information requirements were determined, the precise source of each item of information could not be known, only its discipline. The information flows were then attached to the appropriate tasks as either inputs or outputs using the IDEF0v notation described in figure 3. The DPM consists of some 150 diagrams, 600 design tasks and 4,000 information requirements.

Figures 5 shows examples of diagrams from the detailed building design model. The DPM hierarchy can be traced from activity A3, 'Structural Design', through activity A34, 'Secondary Structure Design, and A342, 'Lift Shaft Structure Design' to design tasks at the bottom of the hierarchy (activities A3421, A3422, A3423). Activity A31, 'Check / Revise Structural Design Information' is also an individual design task. It is not partitioned or represented in the matrix analysis stage of the methodology because it deals with grouped information rather than information produced and required by other design tasks. It can be seen that detailed information flows are represented at the bottom level of the hierarchy, however at upper levels, the information flows are grouped under headings that ensure the diagrams do not become too confusing. 


\subsection{Verifying the Design Process Model}

Following its compilation, the consistency and integrity of each section of the building DPM was checked by the research team through the use of functions within the proprietary CASE tool. The diagrams were then examined by designers from a different organisation to the one which helped in compiling them. This was, in effect, the first test of the hypothesis relating to the construction of a largely non-specific (i.e. generic) design process for buildings and the result was very encouraging considering the small and relatively trivial changes required to suit the second organisation. Comments were incorporated into the diagrams, where appropriate, before a second version of the diagrams was sent to both the design organisations for final comments and confirmation. The resulting non-specific design process model was then used as the basis for the creation of project-specific models on the case study projects (section 5). Clearly, further verification of the model will occur as it is exposed to more design organisations and projects.

\subsection{Design Information Classification}

\subsubsection{Compiling Design Information Classifications}

The dependency structure matrix analysis stage of the ADePT methodology not only represents the activities in the DPM and the dependencies between them, but indicates the level of dependency and schedules the process on this basis. The information requirements were tabulated in the same form as was used to compile the DPM. Information classifications were allocated to each information flow by practising designers from the collaborating organisations. Classifications were made on a three point scale: A being the most critical information and C being the least. Where a generic classification could not be determined, designers indicated that there would be more than one possible classification depending on the features of the project. This meant that six alternative generic classifications were made: A, B, C, A/B, B/C and A-C. Information classifications were made on the basis of three factors; strength of dependency of the task on the information; sensitivity of the task to slight changes in the information; and the ease with which the information can be estimated, as shown in figure 6 . 


\subsubsection{Verifying Design Information Classifications}

The table of information classifications was verified by designers from an alternative organisation to the one which supplied information compiled the table. Comments and suggestions were evaluated and discussed with both the designers responsible for compiling and verifying the information, before finalising the generic information classifications table.

\section{FEATURES OF THE DESIGN PROCESS MODEL}

\subsection{Discipline Specific Features}

The hierarchical structure of the building Design Process Model (DPM) has different characteristics for each discipline because of variations in the way the disciplines undertake their work. This applies particularly to architecture and engineering. The following section describes the main structure of the DPM within each discipline, summarising the breakdown into systems of the building and then into sub-systems and components.

The architectural design process (activity A1) contains a series of activities related to the design of architectural systems. The design tasks within the architectural section of the model are closely associated with the production of drawings and specifications. This is markedly different from the engineering disciplines' design processes, where tasks are more concerned with the development of the design, and is a reflection on the way architects work. The architectural development of the design is largely completed prior to the detailed design stage of the building project and therefore work undertaken during the stage is primarily in the production of drawings.

The civil and structural engineering processes (activities A2 and A3) are sub-divided into the design of systems in a similar manner to architecture. The division between the civil and structural engineering disciplines occurs at ground level of a building, as agreed with practising designers during the DPM creation and verification. The design of the ground floor slab and systems beneath it are civil engineering activities, while the design of above ground systems are represented within the structural engineering model. A further feature of the civil 
engineering section of the DPM is that it contains 'options' for various systems of the building. For example, two options exist for the design of foundations: 'Piled Foundation Design' and 'Spread Foundation Design'.

The mechanical engineering section (activity A4) is sub-divided into the design of a range mechanical services systems. The design of each mechanical services system is decomposed further into 'Requirements and Load Analysis', 'Schematic Design', ‘Plant Layout Design' and 'System Specifications' which are in turn broken down into individual design tasks.

Like the mechanical engineering discipline, the electrical engineering section of the DPM (activity A5) is divided into engineering systems. However, at the first partition the electrical engineering process is represented in terms of 'groups' of systems such as 'Lighting Systems Design' and 'Communications Systems Design' before being decomposed further into systems such as 'General Lighting Design' and 'Emergency Lighting Design' and then into individual design tasks.

\subsection{Cross-Disciplinary Characteristics of the Design Process Model}

\subsubsection{Structure}

The detailed building design process is decomposed into design activities to be undertaken by the five design disciplines: architecture, civil engineering, structural engineering, mechanical engineering and electrical engineering. It is apparent from interviews with design managers that in some cases, more than these five disciplines may be involved in the design. For example, public health engineering and fire engineering are regularly undertaken by specialist consultants. These instances need to be noted at the beginning of a project so that either the DPM can be modified to show the specialist disciplines, or the activities within the scope of responsibility of the specialist disciplines can be highlighted at the programming stage.

The building's systems appear in the hierarchy under the discipline where they best suit the design and management methods of the design organisations interviewed during the research. In some cases, it would be appropriate for the design of systems to be undertaken by designers 
in a discipline other than the one indicated by the DPM. Examples of instances where design could feasibly be undertaken by more than one discipline are: lifts (architectural or electrical engineering); foundations (civil engineering or structural engineering); and external works (architectural or civil engineering). Again, these issues need to be noted at the beginning of a project so that either the DPM can be modified accordingly, or the activities can be allocated to the appropriate discipline at the programming stage.

The scope of the DPM and the information within it attempts to describe the process at a nonspecific level. That is to say that the DPM represents the process of design of a building which contains common systems and elements, including suitable options where appropriate. As a result of this, at the stage where the model is used to represent the design process for a specific project, it will require some manipulation to represent the process accurately. This will mean that some sections of the DPM will have to be deleted (for example, one of the options for 'foundation design' would normally be deleted), some sections added and some altered (for instance, some information flows may need to be reviewed to account for the location of components in the building). The extent of the applicability of the model to a range of building types can only be ascertained by its repeated application to new projects, with the expectation that it will evolve and increase in genericicity. As will be shown later, the current model accounted for over $90 \%$ of the design activities in the test projects.

\subsubsection{System, components and activities}

Each activity in the DPM in referenced with a unique number. This number, which is prefixed with the letter A (for activity), indicates the location of the activity within the process hierarchy. For example; design task 'LPHW (Low Pressure Hot Water) Pipe Work Pressure Loss Calculation' is activity number A4324 which is the fourth task at a level below A432, 'LPHW Schematic Design', in the hierarchy which is in turn below A43, 'LPHW System Design', and A4, 'Mechanical Services Design'.

Each system within the building is represented once in the DPM. However, in some projects various parts of the building may be present more than once, for example, two or more 
specialist lighting systems may be required. Where this is the case, the relevant part of the DPM will need to be duplicated together with the corresponding information flows.

The choice of some systems of the building is dependent on the construction methods being used, the site, the client and other influences. This means that options for different types of system need to be included in the DPM. For example, a number of different foundation design, power supply design, and lighting design activities exist. Any of these activities that are not required during a project must be removed from the DPM at the beginning of the design.

Activities are described by a noun. For example, 'General Lighting Layouts', 'Lift Requirements' or 'Steam Heating Load Calculation'. The procedure itself is that of performing, determining or establishing the activity described.

\subsubsection{Information flows}

At the high levels of the DPM, information flows are grouped to ensure that the diagrams do not become unwieldy. For example, at the level of the five main disciplines, all information is grouped into intra-disciplinary design information, cross-disciplinary design information, and draft (or unchecked) design information. At levels in the DPM where grouped information is separated, the name under which it was grouped at the higher level will be shown. This allows information flows to be traced through the levels of the hierarchy quickly. Grouped information will always be separated at the lowest level of the hierarchy, or at a higher level when this can by achieved without making the diagram cumbersome. Information inputs from external sources are not grouped at higher levels of the DPM but are 'tunnelled' (shown in brackets). This is a technique that ensures the DPM's consistency remains intact.

Where an input is required by an activity from an external source, then the name of the source is given, thereby indicating the origin of the information rather than the nature of the information itself. This is so that a designer can see from the DPM the person to liaise with in order to get the required information. The nature of the information is normally obvious from its source and from the activity it is required by. This approach aims to distinguish between the information from external sources such as standards, design guides, or a previous stage in the 
design process which should be readily available to the designers, and external bodies, where it will be more difficult to ensure that the information flows are timely. 


\section{MODELLING DESIGN INFORMATION LOCATION}

The aim of the building design process model (DPM) is to show the design tasks, indicate the information requirements of these tasks and to identify the source of each item of information. This will then allow the sequencing and programming of the design to take place based on the flow of information within the process. In order to gain the full benefits of the model and programmes based upon it, not only does the nature of the design information need to be represented but also the location of the information within the project. Therefore, it is a further aim of the DPM to define the location of the information illustrated in the model to help coordinate storage, access and retrieval.

The location of documented information within the design process can be described by defining the documents or deliverables that are produced during the detailed design in terms of the information that they show. This will in turn have defined a generic list of project deliverables to be produced as a result of completing the tasks described by the DPM.

\subsection{Design Deliverables Matrix}

Research into the number and nature of typical drawings and schedules produced during the detailed design stage of a project has produced a summary of the usual deliverables. This is shown in table 1 which lists the deliverables in terms of the system with which they are concerned and the type of document that is being produced for the electrical engineering part of the DPM. Table 1 also highlights the task within the model that is responsible for producing the deliverable. Obviously, with an array of information on each deliverable, there are often a number of tasks that contribute to their production. The task number given in the table relates to the individual task that is responsible for the production of the document (which will contain information produced by other tasks).

\subsection{Design Deliverable Definitions}

The CI/SfB Construction Indexing Manual $^{20}$ gives brief definitions of some of the types of document produced during a building design. In order to facilitate the easy location of design 
information, definitions of the various design documents (calculations; location drawings; schematic drawings; etc.) have been formulated, some of which are based on those in the $\mathrm{CI} / \mathrm{SfB}$ Construction Indexing Manual, but updated and with a more detailed description. The design deliverables matrix (table 1) and the definitions of each type of deliverable mean that, having identified the information requirements of a design task by using the DPM, the designer should be able to locate the document or documents on which that information is shown.

\section{VALIDATION AND APPLICATION}

The non-specific DPM has been validated by producing four project-specific models and testing the matrix analysis and programming stages of ADePT on them. A project-specific representation of the design process can be developed in one of three ways:

- The CASE tool can be used to amend the model diagrams before a project-specific table of information dependencies is produced

- A table of information dependencies and classifications based on the non-specific DPM, can be amended before a dependency structure matrix (DSM) is developed

- A DSM produced directly from the non-specific DPM can be amended

Testing to date shows that each approach has benefits and disadvantages over each other in terms of the time taken, ease of operation and accuracy of modelling. Future work will focus on the model's interface with a Windows-style approach to manipulating the model.

The DPM has been tested on a pharmaceutical laboratory, a railway terminal, an office development and a hospital. These projects ranged in value from $£ 16 \mathrm{M}$ to $£ 160 \mathrm{M}$ and table 2 gives details of the size and complexity of the models. This small number of test cases places limits on the validation process, but the results (described below) indicate that the attempt to produce a reasonably generic model, that requires relatively little effort to convert for a specific building, has been successful.

This testing of the DPM has meant that a broad range of design issues have been included in the model validation to date. In formulating a project-specific model of the design process, the 
first task is in ensuring the model content and structure is valid. The former requires the deletion of design activities that are not relevant to the project, and the addition of activities associated with specific features of the building not already covered. There may also be occasions where a section of the model must be duplicated, for example where more than one type of ventilation system is to be designed, then the appropriate section of the model must be repeated. The validity of the model was confirmed further by the largely repeatable nature of its structure, evident from the suitability of a high proportion of tasks to a diverse range of projects, as can be seen in table 2. A limited number of civil and structural tasks are applicable to each of the projects because of the different types of structure (foundations, ground floor slab, frame, etc.) designed in each project. Table 2 shows that despite this, relatively few additions were necessary to compile the model during its testing on the three projects, as various choices for different structural systems are included in the non-specific model.

The second task in modelling a specific project was to review the information requirements of all design tasks. Again, this meant deleting (and on occasions, adding or redirecting) information flows in the model.

\section{CONCLUSIONS}

This paper has described a model of the detailed building design process that is the first stage of the Analytical Design Planning Technique (ADePT). The model has been developed through the production of a revised IDEF0 process modelling notation termed IDEF0v, the implementation of a three-point information classification system and the formulation of an information location matrix and deliverables definitions. The model, information classifications and information matrix have been verified across two organisations and the model has been tested by successfully representing the design of four building projects. It has proved possible to generate the project-specific models in an acceptable time scale. With time, the database of the DPM will grow, increasing its generic nature and reducing the need for special project additions. 
The design process model (DPM) covers a wide range of building systems. This means that the design activities and information dependencies in complex building design problems can be represented and the ADePT planning methodology can be used to programme and manage the design phase of such projects. Practising designers and design managers shown the ADePT methodology have been enthusiastic about the effectiveness of the approach and the detailed nature of the DPM.

Further work will examine the hierarchy of the DPM in relation to the Uniclass system of structuring project information ${ }^{21}$, investigate the relationships between the detailed design stage (represented by the DPM) and other stages of the design process, study various means of formulating project-specific models and test the DPM and ADePT methodology on further building projects.

\section{ACKNOWLEDGEMENTS}

This work has been undertaken as part of a project entitled ‘Design Information Methodology and Tools for the Management of Detailed Building Design'. The research is funded under research grant GR/K74197 by the EPSRC, DETR and industry (AMEC Design and Management, Ove Arup and Partners, BAA, Boots, Laing Management and Sheppard Robson).

\section{REFERENCES}

1 Austin S, Baldwin A and Newton A A Data Flow Model to Plan and Manage the Building Design Process' Journal of Engineering Design Vol 7 No 1 (1996) pp 3-25

2 Austin S, Baldwin A, Li B and Waskett P Development of the ADePT Methodology: An Interim Report on the Link IDAC 100 Project. Loughborough University. ISBN 1897911068 (1998)

3 Steward D Analysis and Management: Structure, Strategy and Design Petrocelli Books, USA (1981)

4 Austin S, Baldwin A, Li B and Waskett P Application of the Analytical Design Planning Technique to Construction Project Management Submitted to Project Management Journal (1998) 
5 Austin S, Baldwin A, Li B and Waskett P Analytical Design Planning Technique (ADePT): A Dependency Structure Matrix Tool to Schedule the Building Design Process Submitted to Construction Management and Economics (1998)

6 Austin S, Baldwin A, Li B and Waskett P Analytical Design Planning Technique (ADePT): Programming the Building Design Process Submitted to Structures and Building (1998)

7 Pugh S Design Activity Models: Worldwide Emergence and Convergence Design Studies Vol 7 No 3 (1986) pp 167-173

8 VDI-Richtlinie 2221 (Entwurf): Methodik zum Entwickeln und Konstruieren Technischer Systeme und Produkte VDI-Verlag, Düsseldorf (1985)

9 Pahl G and Beitz W Engineering Design: A Systematic Approach The Design Council, London (1988)

10 RIBA Plan of Work for Design Team Operation Royal Institute of British Architects, RIBA Publications, London (1973)

11 Pugh S and Morley I E Total Design: Towards a Theory of Total Design Design Division, University of Strathclyde, Glasgow (1988)

12 Pugh S Total Design J. Wiley, London (1990)

13 Sheath D M, Woolley H, Cooper R, Hinks J and Aouad G A Process for Change - The Development of a Generic Design and Construction Protocol for the UK Construction Industry International Construction Information Technology (INCIT 96) Conference Sydney, Australia (1996)

14 Sanvido V E and Norton K J Integrated Design-Process Model Journal of Management in Engineering September/October (1994)

15 Karhu V, Keitilä M and Lahdenperä P Construction Process Model: Generic Present-State Systematisation by IDEF0 Research Notes 1845, VTT, Finland (1997) 
16 Baldwin A, Austin S, Thorpe A and Hassan T Simulating Quality Within the Design Process American Society of Civil Engineers (ASCE) Second Congress on Computing in Civil Engineering Atlanta, Georgia (1995) pp 1475-1482

17 Marca D A and McGowen C L SADT: Structured Analysis and Design Technique McGraw-Hill, New York (1988)

18 Bravoco R R and Yadav S B A Methodology to Model the Dynamic Structure of an Organisation Information Systems Vol 10 No 3 (1985) pp 299-317

19 Court A W, Culley S J, and McMahon C A Information Access Diagrams: A Technique for Analysing the Usage of Design Information Journal of Engineering Design Vol 7 No 1 (1996)

20 Ray-Jones A and McCann W CI/SfB Project Manual: Organising Building Project Information Royal Institute of British Architects, The Architectural Press, London (1971)

21 RIBA Uniclass: Unified Classification for the Construction Industry Royal Institute of British Architects, RIBA Publications, London (1997) 


\section{Figure and Table Captions}

Figure 1 Analytical Design Planning Technique (ADePT)

Figure 2 IDEF0 notation

Figure 3 Modified IDEF0 notation (IDEFOv)

Figure 4 Detailed building design process divided by discipline

Figure 5 Examples of design process diagrams: $A 3 \rightarrow A 34 \rightarrow A 342$

Figure 6 Contrasting Influences on Information Classifications (Austin et al1)

Table 1 Design deliverables matrix for electrical engineering

Table 2 Results of applying the DPM to building projects 


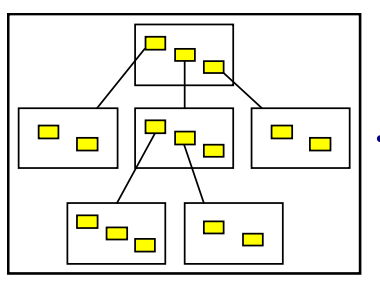

Design Process

Model
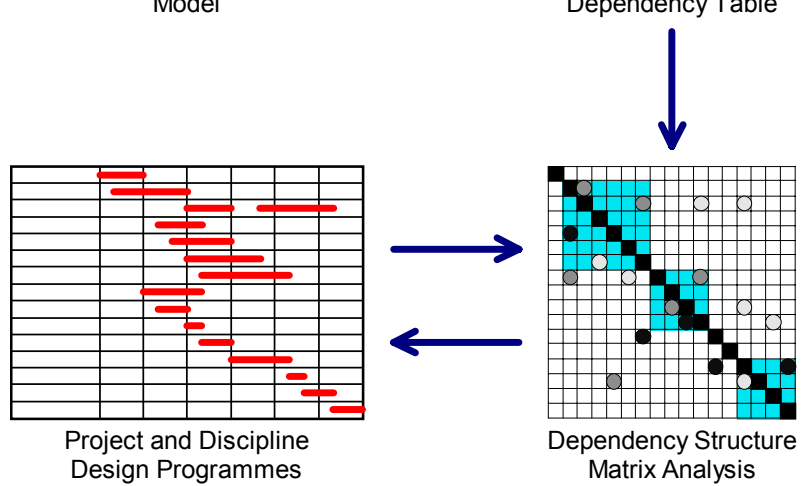

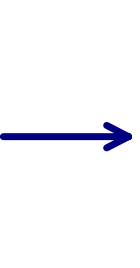

Information

Dependency Table

Figure 1 Analytical Design Planning Technique (ADePT)

Austin et al 


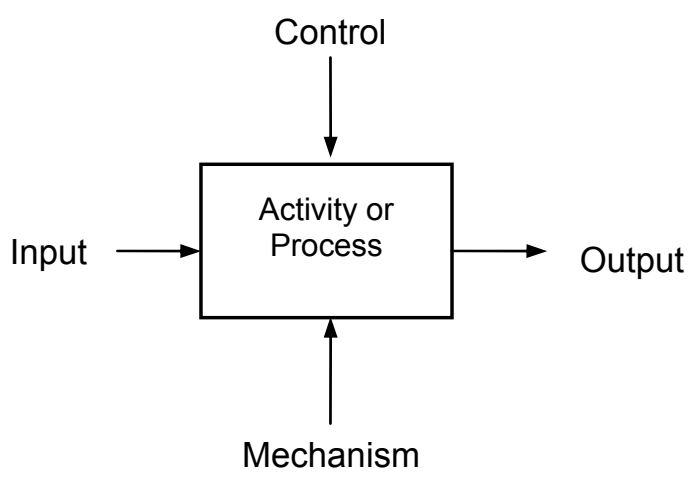

Figure 2 IDEF0 notation

Austin et al 


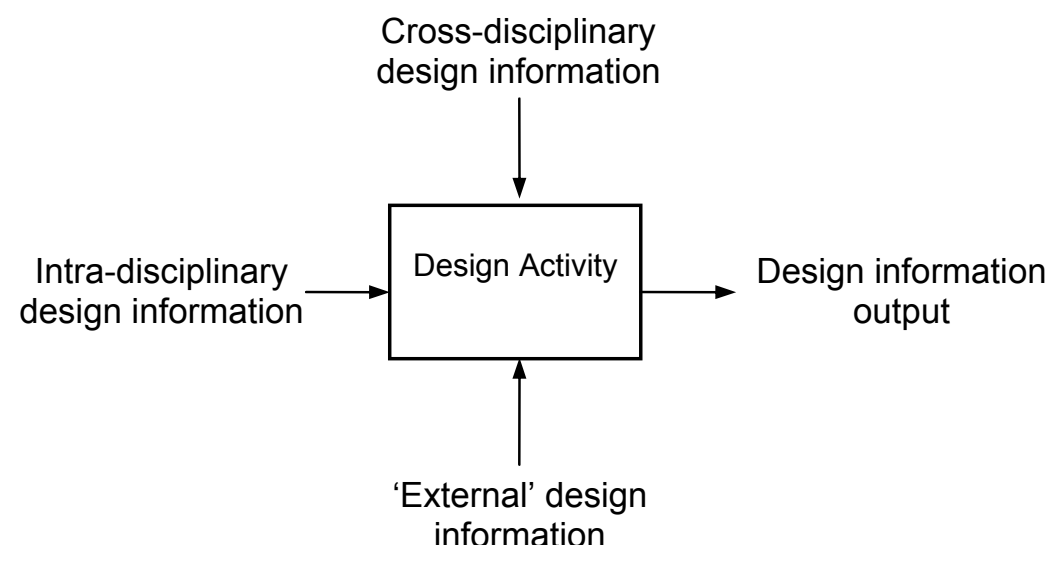

Figure 3 Modified IDEF0 notation (IDEF0v)

Austin et al 


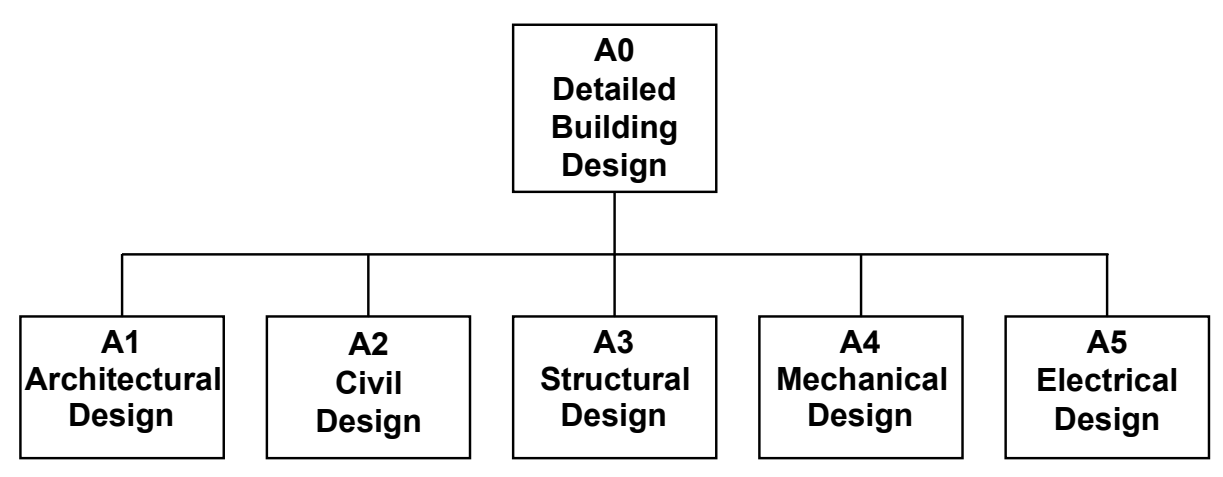

Figure 4 Detailed building design process divided by discipline

Austin et al 


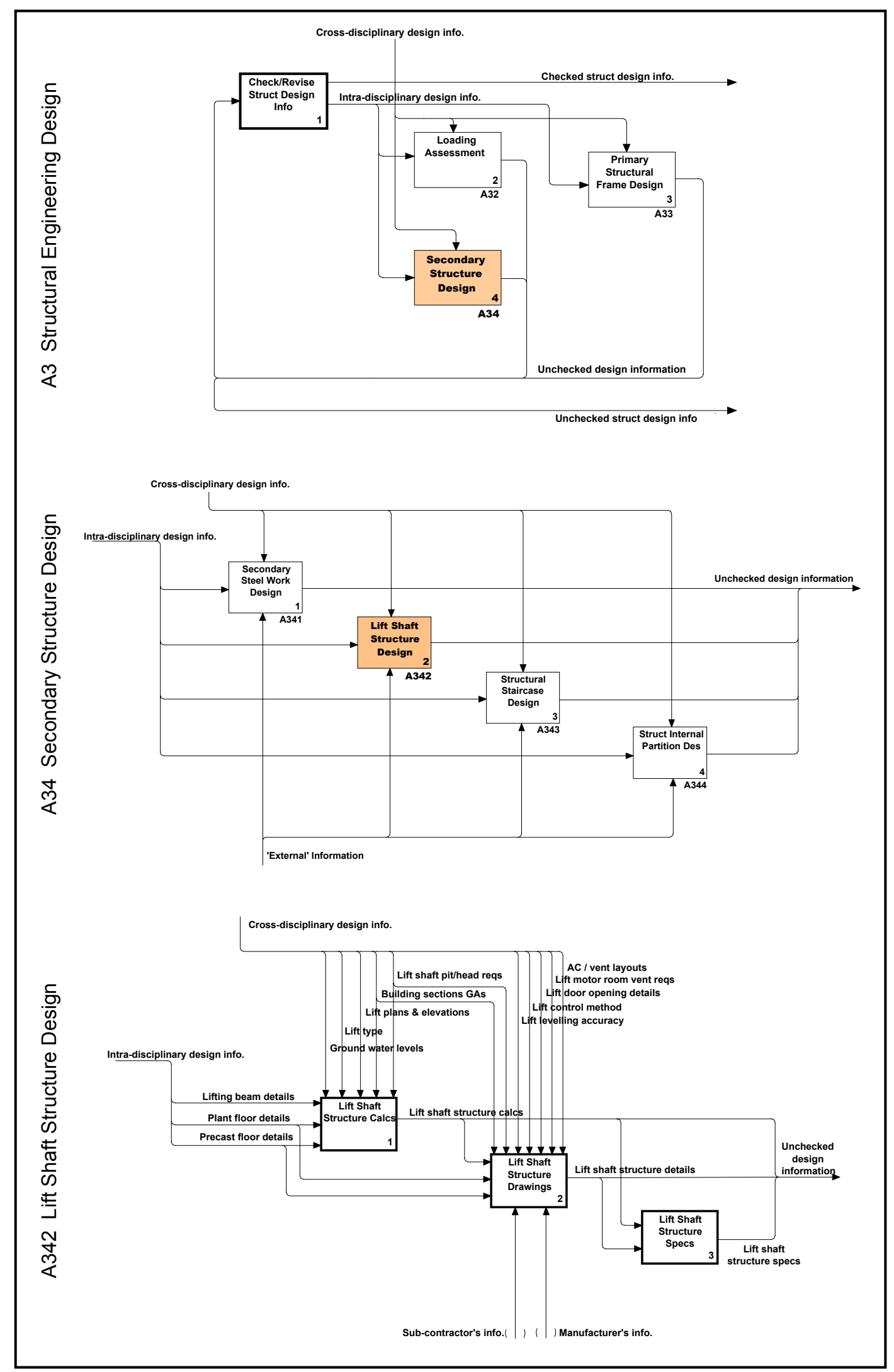

Figure 5 Examples of design process diagrams: $A 3 \rightarrow A 34 \rightarrow A 342$

Austin et al 


\begin{tabular}{|c|c|c|c|}
\hline $\begin{array}{l}\text { Information } \\
\text { flow }\end{array}$ & Task is & Task is & Information is \\
\hline Class A & & & \\
\hline Class B & 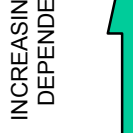 & 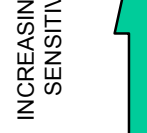 & 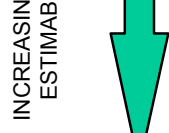 \\
\hline & & & \\
\hline
\end{tabular}

Figure 6 Contrasting Influences on Information Classifications (Austin et al ${ }^{1}$ )

\author{
Austin et al
}




\begin{tabular}{|c|c|c|c|c|c|c|c|c|c|c|}
\hline \multirow[b]{2}{*}{ Building element / system } & \multirow[t]{2}{*}{ Calculations } & \multicolumn{7}{|c|}{ Drawings } & \multirow[t]{2}{*}{ Schedules } & \multirow[t]{2}{*}{ Specs } \\
\hline & & Location & Schematics & GAs & Layouts & Assembly & Component & Details & & \\
\hline High voltage supply \& distribution & A5211 & A52113 & A52121 & A5212 & A52122 & & & & A5211 & A5213 \\
\hline Low voltage supply \& distribution & A5221 & A52213 & A52221 & A5222 & A52222 & & & & A5221 & A5223 \\
\hline Electrical carcassing & & & & & A523 & & & A523 & & A5233 \\
\hline Small power & & & & & A524 & & & & A5244 & A5245 \\
\hline Standby generator & A5251 & & A5252/3 & A5254 & & & & A5255 & & A5257 \\
\hline Uninterruptable power supply & A5261 & A5262 & & & & & & & & A5263 \\
\hline Emergency lighting & A5311 & & A5313/5 & & A5312 & & & & & A5317 \\
\hline General lighting & A5321 & & A5324/8 & & A5323 & & & & A5326 & A5.3.2.10 \\
\hline External lighting & A5331 & & A5333 & & A5332 & & & & A5335 & A5337 \\
\hline Specialist lighting & A5341 & & A5343 & & A5342 & & & & A5345 & A5347 \\
\hline Telecomms & & A5412 & & & A5413 & & & & & A5417 \\
\hline Paging \& staff location & & A5421 & & & A5423 & & & & A5424 & A5426 \\
\hline Public address & & A5433 & A5432 & & A5434 & & & & & A5436 \\
\hline Radio \& TV & & A5442 & A5441 & & A5443/4 & & & & A5447 & A5448 \\
\hline Clocks & & A5451 & A5452/3 & & A5453 & & & A5455 & A5454 & A5457 \\
\hline Data transmission & & A5462 & A5461 & & A5465 & & & & A5466 & A5467 \\
\hline Access control & & & A5511 & & A5512/5 & & & A5512 & & A5516 \\
\hline Intruder detection & & & A5522 & & A5523/6 & & & & & A5527 \\
\hline СстV & & A5532 & A5531/6 & & A5533/4 & & & & & A5538 \\
\hline Fire detection \& alarm & A5611 & & A5612 & & A5613/6 & & & & & A5617 \\
\hline Earthing \& bonding & & & A5623 & & A5625 & & & & & A5626 \\
\hline Lightning protection & & A5632-4 & & & A5635 & & & & & A5636 \\
\hline Lifts & A5711 & & A5715 & & A5713 & & & A5714 & & A5717 \\
\hline Escalators & A5721 & & & & & & & A5723 & & A5726 \\
\hline Moving pavements & A5731 & & & & & & & A5733 & & A5736 \\
\hline Hoists & A5741 & & & & & & & A5745 & & A5746 \\
\hline Cranes & A5751 & & & & & & & A5753 & & A5754 \\
\hline Central monitoring & A581 & A582 & & & A584 & & & & & A585 \\
\hline
\end{tabular}

Table 1 Design deliverables matrix for electrical engineering

Austin et al 


\begin{tabular}{|c|c|c|c|c|c|}
\hline \multicolumn{2}{|l|}{ Project } & A & B & C & $\mathrm{D}$ \\
\hline \multicolumn{2}{|l|}{ Description } & $\begin{array}{c}\text { Pharmaceutical } \\
\text { laboratory }\end{array}$ & Railway terminal & $\begin{array}{c}\text { Office } \\
\text { development }\end{array}$ & Hospital \\
\hline \multirow[t]{4}{*}{ No. of design tasks } & Deleted & 207 & 261 & 242 & 212 \\
\hline & Added & 12 & 28 & 6 & 71 \\
\hline & Reproduced & 23 & 8 & 0 & 348 \\
\hline & Total & 410 & 357 & 346 & 789 \\
\hline \multirow{5}{*}{$\begin{array}{l}\text { Number of tasks } \\
\text { in each discipline } \\
\text { common to all projects }\end{array}$} & Architecture & \multicolumn{4}{|c|}{51} \\
\hline & Civil Eng. & \multicolumn{4}{|c|}{9} \\
\hline & Struct. Eng. & \multicolumn{4}{|c|}{26} \\
\hline & Mech. Eng. & \multicolumn{4}{|c|}{91} \\
\hline & Elec. Eng. & \multicolumn{4}{|c|}{104} \\
\hline \multicolumn{2}{|c|}{ Relevant proportion of generic model tasks } & $98 \%$ & $96 \%$ & $99 \%$ & $91 \%$ \\
\hline \multicolumn{2}{|l|}{ No. of data flows } & 2,406 & 2,804 & 2,656 & 10,015 \\
\hline \multicolumn{2}{|l|}{ Hours to generate } & 16 & 20 & 12 & 40 \\
\hline
\end{tabular}

Table 2 Results of applying the DPM to building projects

Austin et al 